\title{
Pretargeted imaging and radioimmunotherapy of cancer using antibodies and bioorthogonal chemistry
}

\section{Floor C. J. van de Watering ${ }^{1}$, Mark Rijpkema ${ }^{1}$, Marc Robillard ${ }^{2}$, Wim J. G. Oyen ${ }^{1}$ and Otto C. Boerman ${ }^{1}$ *}

1 Department of Radiology and Nuclear Medicine, Radboud University Medical Center, Nijmegen, Netherlands

2 Tagworks Pharmaceuticals, Eindhoven, Netherlands

\section{Edited by:}

Jean-Pierre Pouget, INSERM, France

Reviewed by:

Zhen Cheng, Stanford University, USA

Laurence Carroll, Imperial College, UK

\section{*Correspondence:}

Otto C. Boerman, Department of

Radiology and Nuclear Medicine,

Radboud University Medical Center,

Geert Grooteplein Zuid 10, Nijmegen

6525 GA, Netherlands

e-mail: otto.boerman@radboudumc.nl
Selective delivery of radionuclides to tumors may be accomplished using a two-step approach, in which in the first step the tumor is pretargeted with an unlabeled antibody construct and in the second step the tumor is targeted with a radiolabeled small molecule. This results in a more rapid clearance of the radioactivity from normal tissues due to the fast pharmacokinetics of the small molecule as compared to antibodies. In the last decade, several pretargeting approaches have been tested, which have shown improved tumor-tobackground ratios and thus improved imaging and therapy as compared to directly labeled antibodies. In this review, we will discuss the strategies and applications in (pre-)clinical studies of pretargeting concepts based on the use of bispecific antibodies, which are capable of binding to both a target antigen and a radiolabeled peptide. So far, three generations of the bispecific antibody-based pretargeting approach have been studied. The first clinical studies have shown the feasibility and potential for these pretargeting systems to detect and treat tumor lesions. However, to fully integrate the pretargeting approach in clinic, further research should focus on the best regime and pretargeting protocol. Additionally, recent developments in the use of bioorthogonal chemistry for pretargeting of tumors suggest that this chemical pretargeting approach is an attractive alternative strategy for the detection and treatment of tumor lesions.

Keywords: pretargeting, bispecific antibodies, tumor-associated antigen, radioimmunodetection, radioimmunotherapy

\section{INTRODUCTION}

The use of radiolabeled monoclonal antibodies (mAbs) directed against tumor-associated antigens to visualize, characterize, and/or treat tumor lesions has been widely studied in preclinical and clinical studies (1-3). After intravenous injection, the accumulation of the radiolabeled $\mathrm{mAbs}$ in the tumor is slow due to the slow extravasation and tissue penetration of intact antibodies. Various physiological barriers between the circulation and the tumor cell surface, such as the vascular endothelium, the relatively large transport distances, and the high interstitial fluid pressure in tumors, prevent the rapid accretion of the antibodies in the tumor (4). As a result, only a small fraction of the injected activity will localize in the tumor. Despite this inefficient targeting, in various clinical settings this approach can be effective: especially radiosensitive tumors, like Non-Hodgkin's lymphomas, can respond to treatment with radiolabeled anti-CD20 antibodies (5). Effective radioimmunotherapy (RIT) requires high tumor uptake and rapid clearance of radioactivity from normal tissues. Various approaches have been investigated to improve the tumor targeting such as reducing the circulatory half-life of the antibodies (4). Molecular engineering techniques made it possible to produce antibody formats that clear faster from the blood. However, this is the central dilemma in antibody targeting of tumors: on one hand, the high level of $\mathrm{mAb}$ in the circulation is the driving force for the accumulation of the $\mathrm{mAb}$ in the tumor; on the other hand, the clearance from normal tissues should be rapid. Therefore, innovative approaches are needed to enhance tumor accumulation while limiting retention in normal tissues. Pretargeting is an approach to solve this problem. Several pretargeting systems have been developed including the avidin/streptavidin-biotin pretargeting system $(4,6)$ exploiting the extremely high binding affinity between biotin and (strept)avidin $\left(K_{\mathrm{d}}=4 \times 10^{-14} \mathrm{M}\right)(7)$, the DNA-complementary DNA binding pretargeting system, which relies on the high affinity interaction between complementary oligomers (8-11), pretargeting systems based on the use of bispecific antibodies (bsAb), and recently a novel pretargeting approach has been reported based on highly selective bioorthogonal chemical reactions $(12,13)$. All pretargeting systems are promising; however, each of these approaches has its advantages and limitations. For the avidin/streptavidin, the most significant limitation is the immunogenicity of the pretargeting agents: (strept)avidin being a protein that cannot be humanized. Additionally, the presence of endogenous biotin that could interfere with the system and the need to use a clearing agent to remove the residual antibody from the circulation before administration of the radiolabeled biotin limit the application of this system (14). For the DNA-complementary DNA binding pretargeting system, no immunogenic issues or complications due to the presence of competing endogenous species are reported. However, the oligonucleotides need to be modified to prevent rapid degradation by DNases and/or RNases (11). The pretargeting concept based on the use of bsAb directed against both a target antigen and a radiolabeled hapten is carried out in the following 

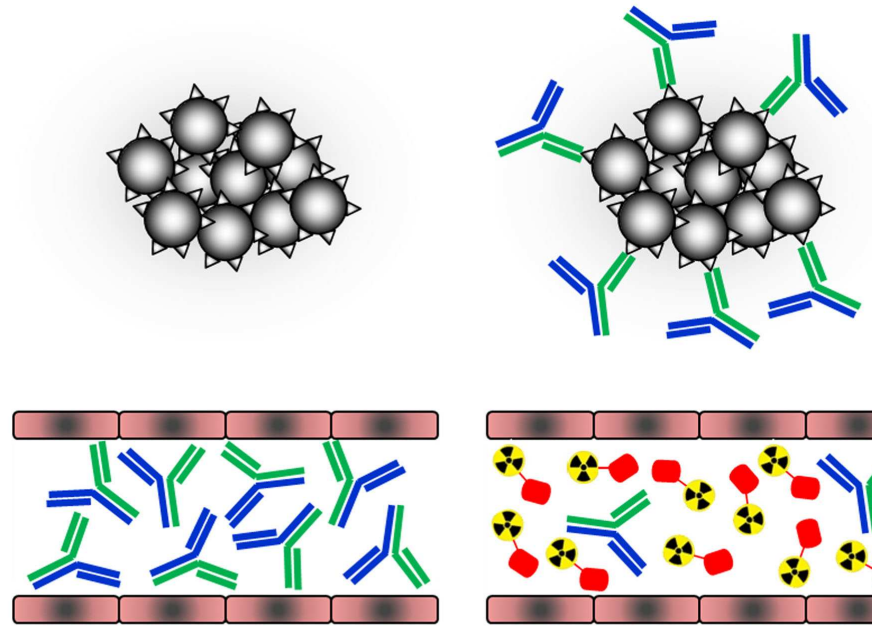

i.v. injection of bispecific Abs

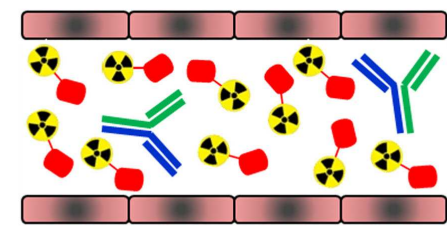

Accumulation of bispecific Abs followed by

i.v. injection of radiolabeled hapten
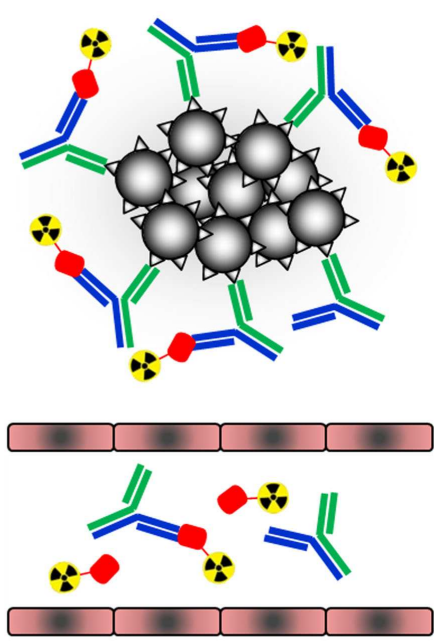

Accumulation of radiolabeled hapten in the tumor

FIGURE 1 | Schematic overview of the pretargeting strategy. First, tumors are pretargeted with bispecific antibodies (bsAb). Secondly, small radiolabeled hapten peptide is i.v. injected and binds to the pretargeted bsAb at the tumor cells.

two steps. In the first step, the bsAb is injected. After the bsAb has accumulated in the tumor due to the specific binding to the tumor-associated antigen and cleared from the blood, the radiolabeled peptide carrying the hapten is administrated. This small molecule will be trapped in the tumor by binding to the bsAb or cleared rapidly from the body via the kidneys. A schematic overview of this pretargeting strategy is shown in Figure 1. Depending on the radionuclide used this pretargeting approach can be used to visualize, or treat tumor lesions, for example, using ${ }^{111} \mathrm{In}$ and ${ }^{99 \mathrm{~m}} \mathrm{Tc}$ for single-photon emission computed tomography (SPECT) imaging, ${ }^{68} \mathrm{Ga}$ or ${ }^{18} \mathrm{~F}$ for positron emission tomography (PET) imaging, or ${ }^{131} \mathrm{I},{ }^{90} \mathrm{Y}$, and ${ }^{177} \mathrm{Lu}$ for pretargeted radioimmunotherapy (PRIT). A significant advantage of this system over the biotin/avidin-based approaches is that the primary pretargeting agent, the bsAb, can be humanized to reduce its immunogenicity. Additionally, the lower affinity of the bsAb-hapten binding compared to the avidin-biotin binding results in the rapid dissociation of the bsAb from the hapten in the circulation, thereby omitting the need for a clearing agent. In the past decade, several improvements on this system have been introduced, which resulted in a flexible universal and efficient pretargeting system. However, the non-covalent binding between the radiolabeled hapten and the bispecific antibody at the tumor cell surface limit the retention of the radiolabeled hapten-peptide in the tumor. Recent developments in the use of bioorthogonal chemistry (cf. the rapid and selective formation of a covalent bond between the pretargeting agent and the radiolabeled agent in vivo) are very promising and show the potential of this system for efficient pretargeting of tumors. Thus, this chemical pretargeting system is an attractive alternative for bsAb-based pretargeting.

In this review, we will focus on the pretargeting concept based on the use of bsAb and additionally discuss the potential and the limitations of this novel bioorthogonal chemistry pretargeting approach.

\section{BISPECIFIC ANTIBODY-BASED PRETARGETING SYSTEMS}

The first studies on the use of a two-step system to target tumors were described by Reardan et al. (15). This group used antibodies against radiolabeled EDTA. This study showed that by separating the antibody tumor targeting from radionuclide targeting improved tumor-to-non-tumor ratios could be obtained (16). These antibodies had no affinity to the tumor and accumulated passively due to the enhanced permeability and retention effect in the tumor $(4,17,18)$. For specific pretargeting of tumors, $\mathrm{bsAb}$ directed against both the tumor-associated antigens and the radiolabeled agent are required.

\section{FIRST GENERATION; ANTI-TUMOR Fab' x ANTI-CHELATE-METAL FAB' FRAGMENTS}

The first generation of bsAb for specific pretargeting methods was chemically conjugated anti-tumor Fab' $\times$ anti-chelate-metal Fab' fragments (6). Several preclinical studies revealed good tumor uptake $(19,20)$. Stickney et al. linked the sulfhydryl groups of $\mathrm{Fab}^{\prime}$ fragments of anti-CEA to those of an anti-benzyl-EDTA to form an $\mathrm{F}\left(\mathrm{ab}^{\prime}\right)_{2}$ bifunctional antibody (19). The potential of this anti-CEA $\times$ anti-benzyl-EDTA $F\left(\mathrm{ab}^{\prime}\right)_{2}$ was evaluated in mice bearing colon tumor xenografts. The anti-CEA $\times$ anti-benzyl-EDTA $\mathrm{Fab}^{\prime} \times \mathrm{Fab}^{\prime}$ was injected $24 \mathrm{~h}$ prior to the i.v. administration of ${ }^{111}$ In-labeled benzyl-EDTA. One day later, the biodistribution revealed a tumor uptake of $18.5 \% \mathrm{ID} / \mathrm{g}$, whereas the blood level was $1.3 \% \mathrm{ID} / \mathrm{g}$. A clinical study was performed to assess the use of this approach in patients with recurrent colon carcinoma. In 14 patients, 20 of the 21 known tumor lesions were detected by scintigraphic imaging. Additionally, nine unknown lesions were detected of which eight could be confirmed. 


\section{SECOND GENERATION; THE USE OF A DIVALENT RADIOLABELED HAPTEN-PEPTIDE}

The pretargeting system using anti-tumor $\mathrm{Fab}^{\prime} \times$ anti-chelatemetal $\mathrm{Fab}^{\prime}$ fragments was based on monovalent binding to the chelate-radiometal complex at the tumor. The stability of such a complex is limited and rapid release of the radiolabeled chelate from the tumor may occur (21). Le Dousall et al. reported improved stability of the complex using divalent haptenpeptide (22). In BALB/c mice i.v. injection of bsAb directed against the lyb8.2 antigen and the hapten dinitrophenyl (DNP) followed by either the mono [ $N-\varepsilon$-(2,4-dinitropheny1)-L-lysyldiethylenetriaminepentaacetic acid (DNP-DTPA)] or divalent (di-DNP-DTPA).

The ${ }^{125}$ I-divalent DNP derivative exhibited a significantly higher binding as compared to the monovalent derivative to the pretargeted cells (for monovalent 23 vs. $65 \% \mathrm{ID} / \mathrm{g}$ for the divalent derivative). It was hypothesized that at the cell surface the divalent hapten could cross-link two bsAbs thereby stabilizing not only the binding to the bsAb but also the bsAb binding to the tumor. This so-called affinity enhancement system (AES) improved tumor targeting and retention of the radiolabeled di-hapten-peptide (20, 22). This AES was confirmed by different groups in several animal models, in which enhanced tumor uptake and improved retention of the radiolabeled di-hapten-peptide was observed (23-28). For example, the use of a bsAb in combination with a divalent ${ }^{111}$ In-DTPA-peptide resulted in a tumor uptake of $3.5 \% \mathrm{ID} / \mathrm{g}$ whereas the tumor uptake of the monovalent DTPA was $2.8 \% \mathrm{ID} / \mathrm{g}$ in mice with s.c. A375 melanoma xenograft. A pronounced AES effect was observed in nude mice with RCC xenografts using bsAb directed against the renal cell carcinoma-associated antigen G250, in combination with a divalent hapten-peptide, Phe-Lys(DTPA${ }^{111} \mathrm{In}$ )-Tyr-Lys(DTPA- $\left.{ }^{111} \mathrm{In}\right),{ }^{111}$ In-di-DTPA (16). At $1 \mathrm{~h}$ p.i. of the hapten, an almost 10 -fold higher tumor uptake of ${ }^{111}$ In-diDTPA $(80 \% \mathrm{ID} / \mathrm{g})$ was observed as compared to the monovalent ${ }^{111}$ In-DTPA (9\%ID/g; Figure 2). Moreover, the retention of the radiolabel in the tumor at $72 \mathrm{~h}$ p.i. was significantly higher for the ${ }^{111}$ In-di-DTPA ( $93 \pm 41 \% \mathrm{ID} / \mathrm{g}$ ) compared to ${ }^{111} \mathrm{In}$-DTPA $(0.9 \pm 0.1 \% \mathrm{ID} / \mathrm{g})$.

Based on the promising preclinical studies, a clinical trial was performed to evaluate the pretargeting approach in patients with primary colorectal cancers. In 11 patients with primary colorectal carcinoma tumors, anti-CEA $\times$ anti-DTPA Fab ${ }^{\prime}-\mathrm{Fab}^{\prime}$ antibody was injected followed $2-8$ days later by ${ }^{111}$ In-labeled $N-\alpha$ (In-DTPA)-tyrosyl- $N$ - $\varepsilon$-(In-DTPA)-lysin ( ${ }^{111}$ In-di-DTPA) (29). For comparison, six patients with similar clinical status were injected with ${ }^{111}$ In-anti-CEA $\mathrm{F}\left(\mathrm{ab}^{\prime}\right)_{2}$. At $1-4$ days p.i. of ${ }^{111}$ Indi-DTPA, the biodistribution results revealed a tumor uptake of $1.8-17.5 \% \mathrm{ID} / \mathrm{kg}$ and were similar to the tumor uptake of ${ }^{111}$ In-anti-CEA F $\left(\mathrm{ab}^{\prime}\right)_{2}(5.5-30.2 \% \mathrm{ID} / \mathrm{kg})$. However, the tumorto-blood (T/B) and the tumor-to-liver (T/L) ratios were significantly improved in the pretargeting approach: 7.8 vs. 4.2 and 2.8 vs. 0.8 , respectively (29).

Besides using a pretargeting approach to detect tumor lesions, the pretargeting approach was also tested to treat tumor lesions. A clinical trial was conducted to estimate the dose delivered to tumor targets and normal tissues using a pretargeting approach consisting of bsAb anti-CEA $\times$ anti-DTPA and ${ }^{131}$ I-diDTPA (30).

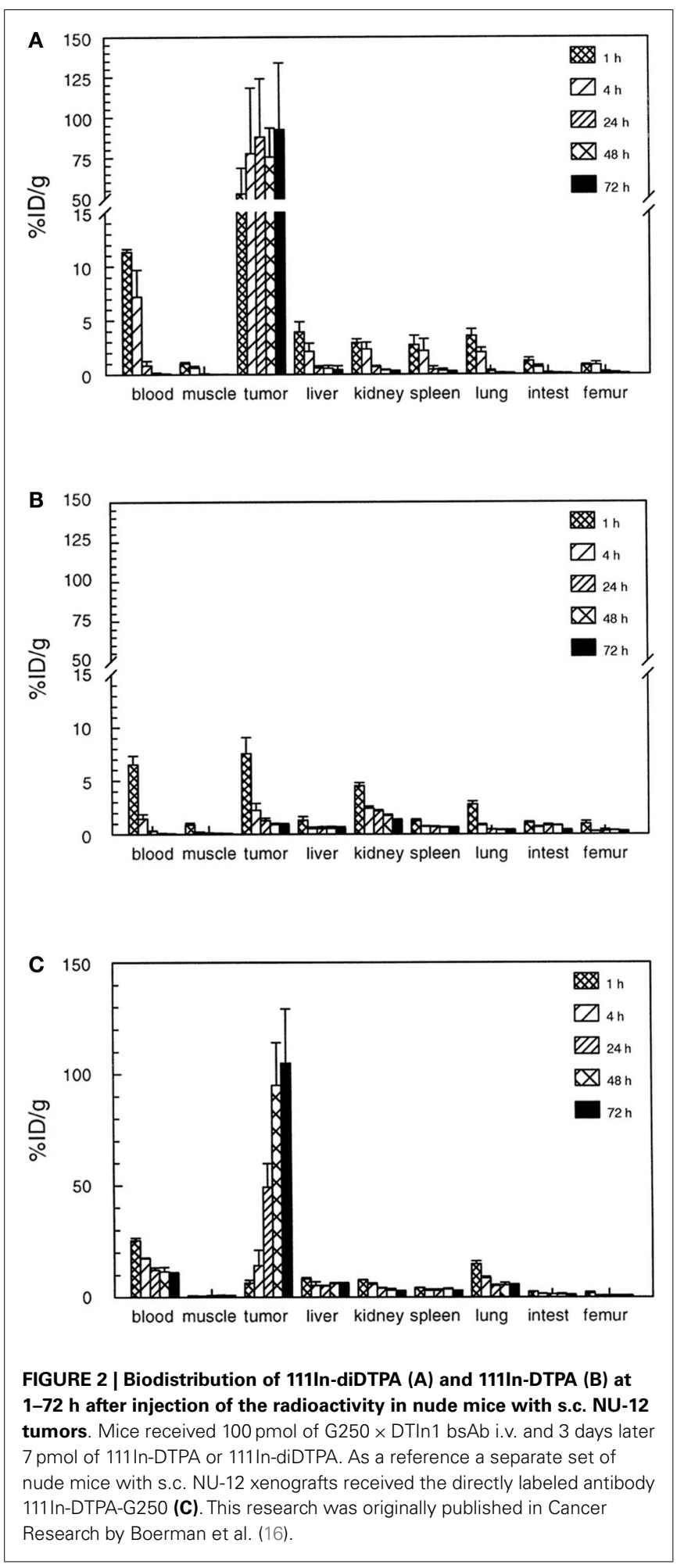

In the clinical trial patients with recurrent medullary thyroid carcinoma (MTC; five patients) and small-cell lung cancer (SCLC; five patients) were pretargeted with a bsAb anti-CEA $\times$ anti-DTPA $\mathrm{Fab}^{\prime}-\mathrm{Fab}^{\prime}(0.1-0.3 \mathrm{mg} / \mathrm{kg})$ and 4 days later $6 \mathrm{nmol}(5.8-9.8 \mathrm{mCi})$ of ${ }^{131} \mathrm{I}$-di-DTPA was administrated. The patients were included 
based on the CEA expression as evaluated by immunohistochemical analysis of the biopsy of their primary tumor. The tumor uptake of ${ }^{131}$ I-di-DTPA and the activity dose to the tumor was significant higher in MTC (average uptake $0.116 \% \mathrm{ID} / \mathrm{g}$; dose ranged from 4.8 to $135 \mathrm{cGy} / \mathrm{mCi}$ ) than in SCLC (average uptake $0.009 \% \mathrm{ID} / \mathrm{g}$; dose ranged from 1.9 to $8 \mathrm{cGy} / \mathrm{mCi}$ ), indicating that the MTC is a more suitable tumor type for PRIT. The therapeutic efficacy and toxicity of PRIT with escalating doses of bsAb anti-CEA $\times$ anti-DTPA (20-50 mg) and 4 days later followed by ${ }^{131}$ I-di-DTPA $(1.48-3.7 \mathrm{GBq})$ was evaluated in 26 patients with recurrent MTC (24). The dose-limiting toxicity was hematologic and an activity dose of $1.78 \mathrm{GBq} / \mathrm{m}^{2}$ could be injected safely in this group of patients. The maximum tumor uptake ranged from 0.003 to $0.26 \% \mathrm{ID} / \mathrm{g}$ and the tumor doses ranged from 7.9 to $500 \mathrm{~Gy} / \mathrm{MBq}(2.94-184 \mathrm{cGy} / \mathrm{mCi})$. From the 26 patients, 17 patients were included to evaluate the tumor response. The maximal tolerated dose (MTD) of $48 \mathrm{mCi} / \mathrm{m}^{2}$ was administrated to 13 patients. A decrease in tumor mass, serum thyrocalcitonin, and CEA levels was observed in six of the patients receiving the MTD. The tumors that showed a response were generally small (maximum diameter of $37 \mathrm{~mm}$ ).

Despite the promising (pre)clinical outcomes using a divalent hapten-peptide, the antibody dissociation rates were still higher as compared to the high affinity pretargeted avidin-biotin complex $\left(K_{\mathrm{d}}=10^{-14} \mathrm{M}\right.$ for biotin with streptavidin/avidin vs. $10^{-9} \mathrm{M}$ for most antigen-antibody complexes) (7). It was suggested that bsAb divalency to the primary target antigen might result in higher tumor accretion by the pretargeted divalent peptide (21). A bsAb chemically prepared by coupling two Fab' fragments, one with monovalent specificity to CEA and one to ${ }^{111}$ In-DTPA $\left(\mathrm{Fab}^{\prime} \times \mathrm{Fab}^{\prime}\right)$ was compared to bsAb with divalency to CEA. Two divalent CEA bsAb coupled to a DTPA Fab' fragment were composed either of the whole anti-CEA $\operatorname{IgG}\left(\operatorname{IgG} \times \mathrm{Fab}^{\prime}\right)$ or the anti-CEA $\mathrm{F}\left(\mathrm{ab}^{\prime}\right)_{2}$ fragment $\left[\mathrm{F}\left(\mathrm{ab}^{\prime}\right)_{2} \times \mathrm{Fab}^{\prime}\right)$. The antibody constructs differ in molecular weight resulting in different clearance rates from the blood of which the fastest clearance is observed with lowest molecular weight construct, $\mathrm{Fab}^{\prime} \times \mathrm{Fab}^{\prime}$, followed by $\mathrm{F}\left(\mathrm{ab}^{\prime}\right)_{2} \times \mathrm{Fab}^{\prime}$ and slowest for $\mathrm{IgG} \times \mathrm{Fab}^{\prime}$. The highest uptake and retention in the tumor was achieved using the $\operatorname{IgG} \times \mathrm{Fab}^{\prime}$ bsAb conjugate. However, in a pretargeting strategy, the uptake of the ${ }^{111}$ In-di-DTPA peptide $\left({ }^{111}\right.$ In-IMP-192) was highest using $\mathrm{F}\left(\mathrm{ab}^{\prime}\right)_{2} \times \mathrm{Fab}^{\prime}$ conjugate followed by $\mathrm{Fab}^{\prime} \times \mathrm{Fab}^{\prime}$ conjugate and lowest for $\mathrm{IgG} \times \mathrm{Fab}^{\prime}$. At the time of maximum tumor accretion, the IgG $\times \mathrm{Fab}^{\prime}$ in the blood predominantly captured the injected hapten. As a consequence, the three- to fourfold higher tumor accumulation of the IgG $\times$ Fab' $^{\prime}$ could not be exploited in the pretargeting approach. Consequently, to take full advantage of a high uptake and retention in the tumor using a long circulating bsAb, the accessibility of the bsAb remaining in the blood need to be reduced by using a clearing agent (21).

The flexibility of the bsAb pretargeting system is increased using the second generation anti-chelate bsAb as different radionuclides can be used, for example, ${ }^{111}$ In $(21,29)$ for imaging and ${ }^{131}$ I for treatment $(24,30)$. However, the binding affinity can be affected by the chelated metal. For example, the affinity of the anti-DTPA antibody, designated 734, to various radiometal labeled DTPA varies from $10^{-9} \mathrm{M}$ for In-DTPA to $10^{-3} \mathrm{M}$ for Ca-DTPA (31).
Additionally, the anti-(In)DTPA had a much lower affinity for DTPA with other radiometals such as ${ }^{90} \mathrm{Y}$ or ${ }^{177} \mathrm{Lu}$. Therefore, it appeared that imaging radionuclides require different antibodies directed against the specific anti-chelate-metal complex than the radionuclides of therapeutic interest.

\section{THIRD GENERATION; BISPECIFIC F(ab')2 \\ ANTI-CEA x ANTI-HISTAMINE-SUCCINYL-GLYCINE}

A more universal/flexible pretargeting system was developed by using an anti-hapten antibody not directed against the chelated radiometal, but directed against the histamine-succinyl-glycine (HSG) hapten $(22,32,33)$. The HSG hapten itself is not involved in binding the radionuclide and thus other chelates suitable for binding radionuclides can be added, for example, the HSG peptides can be conjugated with various chelating moieties such as DTPA, DOTA, or N3S chelates for radiolabeling with In111, Lu-177/Y-90, or Tc-99m/Re-188, respectively or with other agents/moieties such as fluorophores for fluorescence imaging. Sharkey et al. showed the potential of this system by using the bispecific anti-CEA F $\left(\mathrm{ab}^{\prime}\right)_{2} \times$ anti-HSG Fab in combination with HSG peptides labeled with either ${ }^{99} \mathrm{~m}$ Tc or ${ }^{188} \mathrm{Re}$ via an N3S chelate or with ${ }^{111} \mathrm{In},{ }^{177} \mathrm{Lu}$, and ${ }^{90} \mathrm{Y}$ via a DOTA moiety (32). In nude mice with human colon tumor xenografts, this trivalent anti-CEA $\times$ anti-HSG bsAb was injected $24-48 \mathrm{~h}$ prior to the i.v. administration of the divalent radiolabeled HSG peptides, ${ }^{111}$ In-IMP241, ${ }^{177} \mathrm{Lu}-\mathrm{IMP} 241$, and ${ }^{99 \mathrm{~m}}$ Tc-IMP243. The tumor uptake of radiolabeled HSG peptides after pretargeting with the bsAb was significantly higher than with the peptides alone (for ${ }^{111}$ In-IMP241 $0.03 \pm 0.02$ vs. $2.54 \pm 1.04 \% \mathrm{ID} / g$, for ${ }^{177} \mathrm{Lu}-\mathrm{IMP} 2410.03 \pm 0.01$ vs. $2.59 \pm 0.3 \% \mathrm{ID} / \mathrm{g}$, and for ${ }^{99 \mathrm{~m}} \mathrm{Tc}-$ IMP243 $0.1 \pm 0.02$ vs. $7.36 \pm 3.19 \% \mathrm{ID} / \mathrm{g})$. The tumor-to-normal tissue ratio exceeded $8: 1$ within $3 \mathrm{~h}$ p.i. of the hapten-peptide. Consequently, this provides the opportunity to use the same HSG peptide for different purposes depending on the radionuclide used, for example, using ${ }^{111} \mathrm{In}$ and ${ }^{99 \mathrm{~m}}$ Tc-labeled HSG peptide for SPECT imaging, ${ }^{124} \mathrm{I},{ }^{68} \mathrm{Ga}$, or ${ }^{18} \mathrm{~F}$-labeled HSG peptide for PET imaging or ${ }^{131} \mathrm{I},{ }^{90} \mathrm{Y}$, and ${ }^{177} \mathrm{Lu}$-labeled HSG peptide for PRIT (32-38). Besides the flexibility of the system, Sharkey et al. showed that the hapten-peptide structure can alter the biodistribution and clearance of the construct. The liver and kidneys uptake of ${ }^{99 \mathrm{~m}} \mathrm{Tc}$-hapten-peptide consisting of a N3S chelate and DOTA (IMP245) was significantly lower compared to the ${ }^{99 \mathrm{~m}}$ Tc-haptenpeptide bearing only the N3S chelate whereas the tumor uptake and retention did not change. Therefore, when less background is essential around the kidneys and/or urinary bladder, the preferable renal elimination can be altered to a more hepatic elimination by modifying the hapten-peptide construct.

Further improvements were obtained using a recombinant bispecific trivalent construct, hBS14, with bivalent CEA binding and a monovalent HSG binding (39). The trivalent antibody was produced by myeloma cells transfected with hBS14-pdHL2 DNA vector and purified to near homogeneity in a single step using a novel HSG-based affinity chromatography system. In nude mice bearing a CEA-expressing GW-39 human colon tumor xenograft the efficacy of the ${ }^{125} \mathrm{I}-\mathrm{hBS} 14(0.4 \mathrm{nmol})$ in combination with the bivalent ${ }^{111} \mathrm{In}$-HSG-hapten $(0.04 \mathrm{nmol} ; 27 \mathrm{~h}$ interval), IMP241, was evaluated. At $3 \mathrm{~h}$ p.i., the ${ }^{111}$ In-IMP241 tumor uptake was 


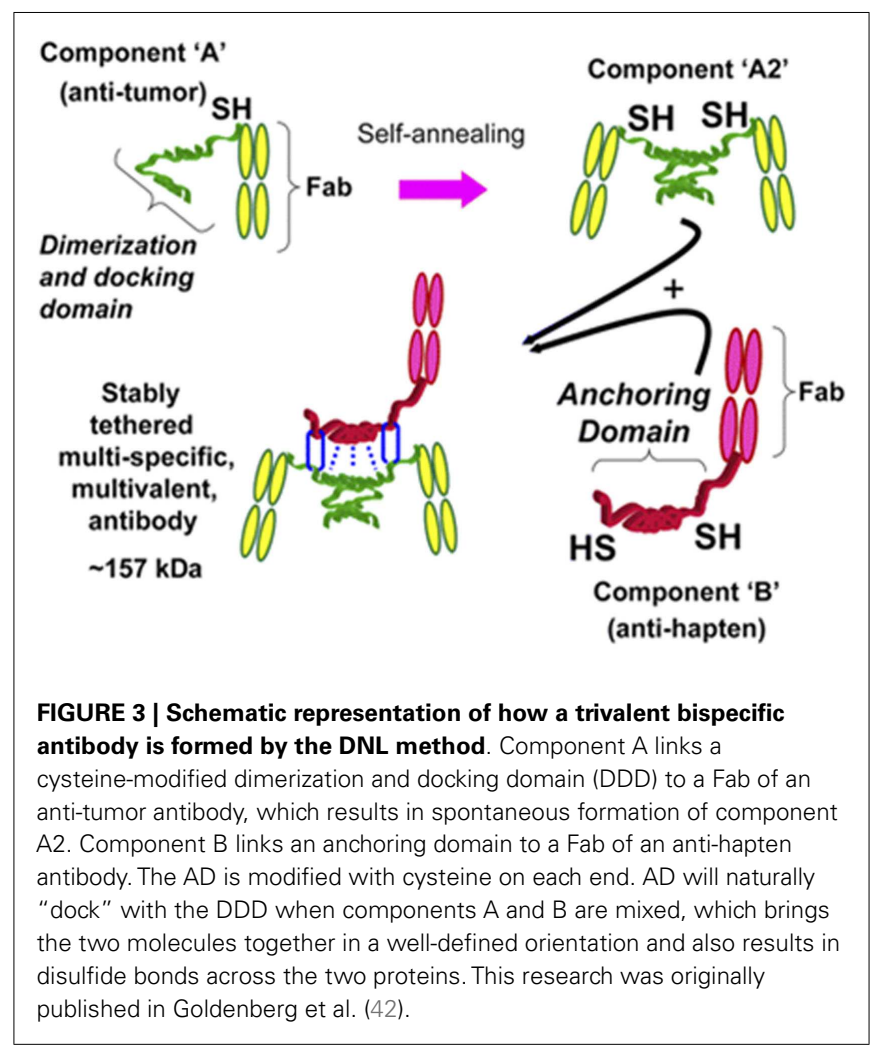

$19.1 \pm 8.7 \% \mathrm{ID} / \mathrm{g}$ and the blood levels were only $0.25 \pm 0.08 \% \mathrm{ID} / \mathrm{g}$ corresponding with a tumor-to-blood ratio of $83 \pm 44 \% \mathrm{ID} / \mathrm{g}$.

Technology that exploits fusing two hybridoma Ab-producing cells using quadroma technology did not produce adequate yields in mammalian cell cultures. Therefore, a new strategy capable of preparing a trivalent bsAb was developed. Humanized trivalent Fab bsAb constructs were produced at a higher yield by the dockand-lock (DNL) technology. The DNL technology is based on the natural association between protein kinase A (PKA; cyclic AMPdependent protein kinase) and A-kinase anchoring proteins. The regulatory subunit of PKA and the anchoring domain of the interactive A-kinase anchoring protein are both attached to a biological entity. The dimeric sequence attached to the anti-tumor $\mathrm{F}(\mathrm{ab})_{2}$ has high affinity for the sequence attached to the anti-hapten Fab, the so-called docking. The stabilization of the trivalent bispecific antibody construct, the so-called locking, is secured by the placement of cysteine residues on four locations within the construct resulting in the formation of disulfide bridges (40-42). A schematic overview of the DNL technology is shown in Figure 3.

Using the DNL technology, several recombinant humanized bsAbs with a divalent antigen specificity and with a monovalent specificity to HSG were produced including an anti-CEA bsAb (TF2) $(43,44)$, an anti-Trop2 (TF12) (45), an anti-CD20 (46), and an anti-MUC1 (47) bsAb.

An effective detection and treatment of tumor lesions using a pretargeting system is best illustrated by the work done on TF2. The ability to detect small micrometastatic human colon cancer nodels $(<0.3 \mathrm{~mm}$ in diameter) in the lungs of nude mice using this system was evaluated and compared to ${ }^{18}$ F-FDG-PET imaging and to TF6, an irrelevant anti-CD22-based bsAb. The tumors were first pretargeted with TF2 and 21-24 h later the ${ }^{124} \mathrm{I}$ or ${ }^{131} \mathrm{I}$ radiolabeled hapten-peptides were injected at a bsAb:hapten molar ratio of 10:1. The TF2-pretargeted tumors in the lungs could be localized at $1.5 \mathrm{~h}$ p.i. of radiolabeled HSG peptide whereas the peptide alone, TF6, or ${ }^{18}$ F-FDG failed. This showed the high potential of the system for sensitive and specific imaging of tumor lesions.

The specificity of the TF2 based pretargeting system was further evaluated using di-HSG peptides radiolabeled with ${ }^{68} \mathrm{Ga}$, a positron emitting radionuclide with a more suitable half-life (68 $\mathrm{min}$ ) for pretargeted imaging purposes than ${ }^{124} \mathrm{I}$ (4.2 days) (48). Nude mice were s.c. implanted with CEA-expressing LS174T human colonic tumor, a CEA-negative tumor, or an inflammation was induced in the thigh muscle. The mice were first i.v. injected with bsAb anti-CEA $\times$ anti-HSG and after $16 \mathrm{~h}$ followed by ${ }^{68} \mathrm{Ga}$-IMP288. At $1 \mathrm{~h}$ p.i., a high specific uptake of ${ }^{68} \mathrm{Ga}$ IMP288 was observed in the tumor $(10.7 \pm 3.6 \% \mathrm{ID} / \mathrm{g})$, whereas the uptake of ${ }^{68} \mathrm{Ga}$-IMP288 in normal tissues, in CEA-negative tumors and inflamed muscle was low (Figure 4). In contrast, ${ }^{18} \mathrm{~F}$-FDG localized efficiently in the tumor, however, also in the inflamed tissue and in a number of normal tissues including liver, spleen, and intestines. The specificity of the pretargeted immuno-PET using TF2 and ${ }^{68}$ Ga-IMP288 was confirmed in mice with small intraperitoneal xenografts (49). All intra-abdominal tumors lesions $>\sim 4 \mathrm{~mm}$ and even a few lesions as small as $\sim 2 \mathrm{~mm}$ were detected. In line with the previous study, the ${ }^{18} \mathrm{~F}$ FDG uptake in all the present tumors was sufficient, however, also an uptake was observed in various normal tissues such as the intestines.

To evaluate the use of the TF2 and ${ }^{177}$ Lu-IMP288 in PRIT, the therapeutic efficacy and toxicity of the system was evaluated in mice with s.c. LS174T tumors (50). The median survival of mice treated with 1, 2, or 3 cycles of PRIT was 24, 45, and 65 days, respectively, whereas in the untreated mice the median survival was 13 days. Additionally, PRIT effectively delayed the tumor growth with limited hematologic toxicity, indicating that PRIT using TF2 and ${ }^{177}$ Lu-IMP288 might be an effective treatment against colon cancer. Furthermore, the biodistribution of ${ }^{111}$ InIMP288 and ${ }^{177}$ Lu-IMP288 in mice with intraperitoneal LS174T tumors was identical as observed by ex vivo counting as well as by pretargeted immuno-SPECT imaging (51). This indicates that pretargeted immuno-SPECT with TF2 and ${ }^{111}$ In-IMP28 can be used for the non-invasive monitoring of the therapeutic efficacy of PRIT with TF2 and ${ }^{177}$ Lu-IMP288 in mice with LS174T lesions.

The preclinical pretargeting studies using TF2 in combination with radiolabeled di-HSG peptides indicated that PRIT can induce tumor growth inhibition. Therefore in the feasibility, safety and therapeutic efficacy of TF2/Lu-177-IMP288 for the treatment of CEA-expressing tumor lesions was investigated in a first-in-man phase I study in patients with advanced colorectal carcinoma. Four dose schedules in cohorts of five patients were evaluated (52). First, the effect of the time interval between administration of TF2 (75 mg) and IMP288 (100 $\mu \mathrm{g})$ was evaluated: 5 days (cohort 1) and 1 day (cohort 2). Additionally, the effect of a higher bsAb 


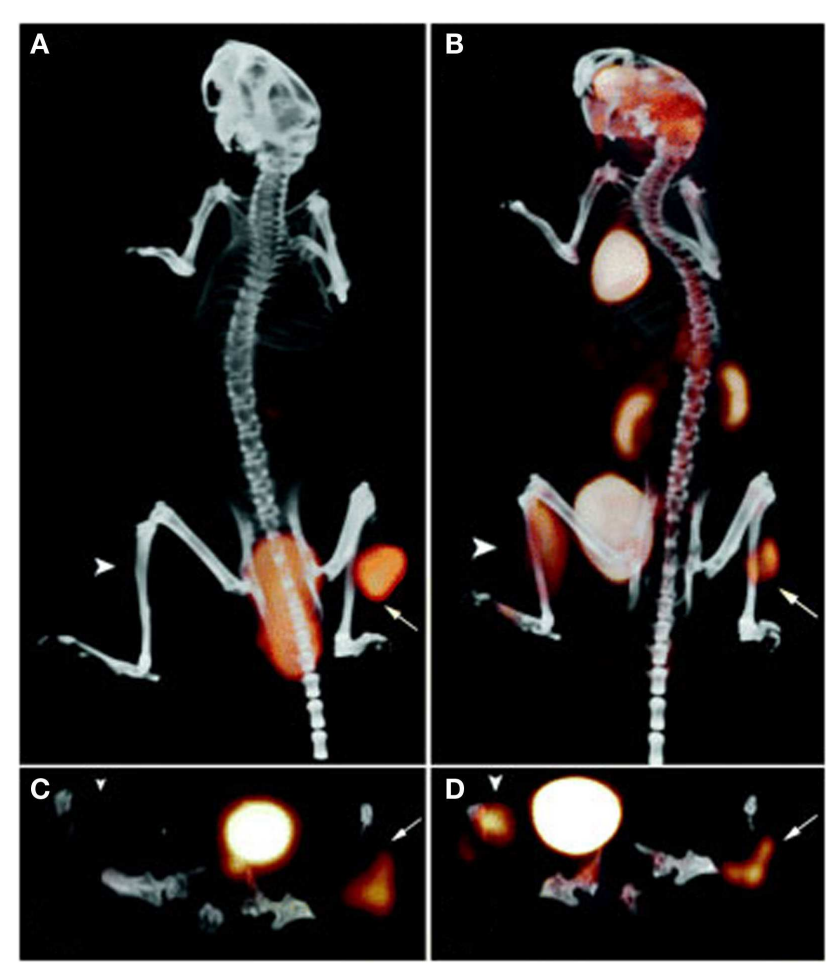

FIGURE 4 | PET/CT images of a BALB/c nude mouse with a s.c. LS174T tumor on the right hind leg (arrow) and an inflammation in the left thigh muscle (arrowhead), which received ${ }^{18} \mathrm{~F}-\mathrm{FDG}$ and, 1 day later, $6.0 \mathrm{nmolTF} 2$ and ${ }^{68} \mathrm{Ga}-I M P 288(0.25 \mathrm{nmol})$ with a $16-\mathrm{h}$ interval. The animal was imaged $1 \mathrm{~h}$ after ${ }^{18} \mathrm{~F}-\mathrm{FDG}$ and ${ }^{68} \mathrm{Ga}-\mathrm{IMP} 288$ injections. The panel shows the three-dimensional volume rendering the pretargeted immuno-PET scan (A) and the FDG-PET scan (B), and the transverse sections of the tumor region of the pretargeted immuno-PET scan (C) and the FDG-PET scan (D). This research was originally published in Schoffelen et al. $(48,50)$ dose (150 mg TF2, 1-day interval, $100 \mu \mathrm{g}$ IMP288, cohort 3) and a lower IMP288 dose (75 mg TF2, 1-day interval, $25 \mu \mathrm{g}$ IMP288, cohort 4) was evaluated. Reducing the time interval and lowering the IMP288 dose resulted in improved tumor targeting. Although it is reported that higher bsAb doses results in improved tumor uptake of the radiolabeled hapten $(48,50)$, no such observations were found using twofold increase of TF2 dose. Co-localization of almost all ${ }^{18}$ F-FDG positive tumors and hapten-peptide with SPECT was observed (Figure 5). Using a high TF2 dose and a low IMP288 peptide dose rapid targeting of tumors was observed, although wash-out of the tumor was observed after $24 \mathrm{~h}$. The patients could tolerate $7.4 \mathrm{GBq}$ of ${ }^{177} \mathrm{Lu}$-IMP288 without experiencing dose-limited toxicity, even though some patients ( 8 out of 20 patients) experienced some level of hematologic toxicity. The TF2 bsAb induced human anti-human antibodies (HAHA) in 11 out of 21 patients. Most likely, the best PRIT regime will be a fractionated multi-dose treatment regimen (e.g., multiple cycles) as observed in preclinical pretargeting experiments (50) and recent clinical trials using ${ }^{90}$ Y-labeled antibodies in combination with gemcitabine (53). However, further clinical studies regarding the pretargeting conditions and protocol are needed.
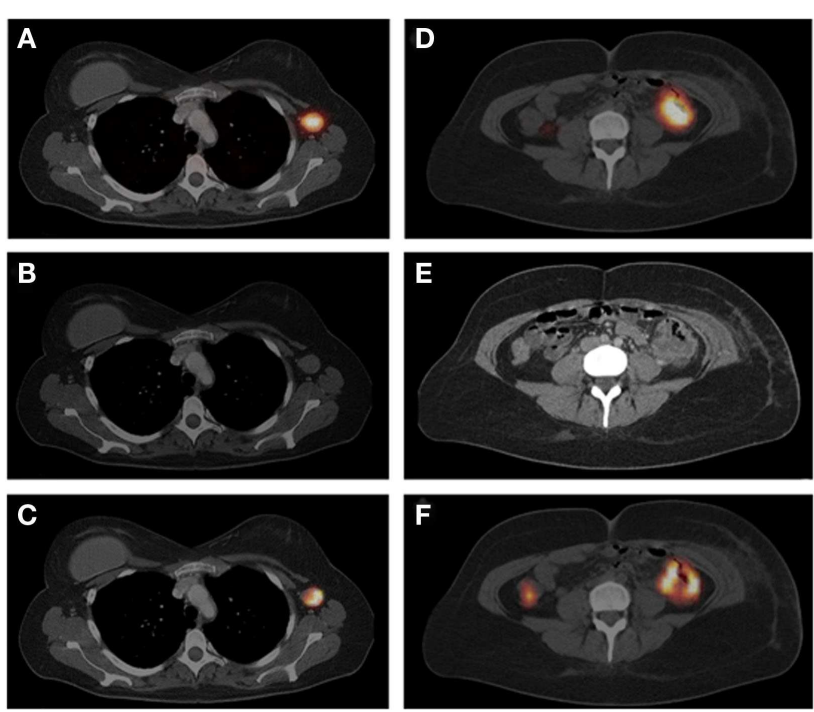

FIGURE 5 |The SPECT/CT image (A), acquired $24 \mathrm{~h}$ after injection of "'1'In-IMP288 (185 MBq, $25 \mu \mathrm{g}$ ), pretargeted with $75 \mathrm{mg} \mathrm{TF2} \mathrm{(1-day}$ interval), in a 38-year-old patient (cohort 4), shows very clear tumor targeting of an axillary lymph-node metastasis, with very low concentrations of radioactivity in normal tissues. Corresponding contrast-enhanced CT scan and a fused FDG-PET/CT scan are shown [(B,C), respectively]. The primary colon tumor $(50 \mathrm{~cm}$ ab ano) also shows highly specific tumor targeting in the SPECT image (D), confirmed by the CT scan and FDG-PET/CT [(E,F), respectively], with non-specific FDG uptake in the ascending colon. This research was originally published in Schoffelen et al. (52).

\section{A DIFFERENT APPROACH; PRETARGETING BASED ON BIOORTHOGONAL CHEMISTRY}

The combination of chemistry and biology has resulted in many innovations and has contributed to our understanding of many biological processes. Nevertheless, many biomolecules including lipids, glycans, and nucleic acids as well as various posttranslational modifications cannot be monitored with genetically encoded reporters as manipulations can interfere with the structure and function of the molecules or the molecules are not genetically encoded. Therefore, new methods were investigated to covalently modify biomolecules in vivo. This has led to the discovery of bioorthogonal reactions to detect, track, or visualize various biomolecules. Using bioorthogonal chemistry, as defined by Bertozzi et al., reactions can occur inside a living organism, which do not interfere or cross-react with naturally occurring functionalities, are reactive under mild and physiological conditions and should not induce cellular toxicity (54). Over the years, several bioorthogonal chemical ligation strategies have been developed including the tetrazine ligation, Staudinger ligation, oxime/hydrazone formation from aldehydes and ketones, and quadricyclane ligation [for reviews on these bioorthogonal chemical reactions see in Ref. (13, $55,56)]$. The archetypical bioorthogonal reaction is the coppercatalyzed 1,3-dipolar Huisgen "click" cycloaddition between azides and alkynes (55). Using this click chemistry, units are joined with heteroatom links (C-X-C) in a modular, rapid, and easy manner without the generation of toxic byproducts (57). The selectivity 
and flexibility as well as the bioorthogonality and speed of click chemistry make it an ideal method for the creation of radiopharmaceuticals, especially ${ }^{18} \mathrm{~F}$-radiolabeled peptides (58). The binding of a radiolabeled probe to the tumor-targeted antibody might also be obtained using bioorthogonal reactions. In general, this chemical approach of pretargeting is less likely to be immunogenic and could provide a universal approach for tagging and in vivo tracking of Abs. However, the need for a copper catalyst in coupling of azide and terminal alkyne to generate a triazole limits the use of the 1,3-Huisgen cycloaddition reaction in biological systems due to the toxicity of copper in vivo. Various bioorthogonal reactions have been developed that do not need the presence of a $\mathrm{Cu}$ catalyst. For example, copper-free click chemistry can be achieved via the relief of strain (strain-promoted azide-alkyne cycloadditions, SPAAC). Alternatively, Blackman et al. reported the very fast reaction kinetics and in vitro bioorthogonality of the inverse-electron-demand Diels-Alder (IEDDA) reaction between trans-cyclooctene (TCO) and electron deficient tetrazines (59). Subsequently, Devaraj et al. tagged the anti-EGFR antibody cetuximab with trans-cyclooctene succinimidyl carbonate and combined with a fluorescent tetrazine probe was able to target A549 cancer cells in serum at $37^{\circ} \mathrm{C}(60)$. A schematic overview depicting the use of TCO-modified $\mathrm{mAb}$ and radiolabeled tetrazine to (pre)target tumors through the IEDDA reaction is shown in Figure 6. The first in vivo proof-of-concept study by Rossin et al. using a chemical pretargeting approach based on the Diels-Alder components demonstrated that the system could manage the more demanding conditions in vivo, including low reagent concentrations and short reaction time, and the prolonged residence time and required in vivo stability for the TCO tag (61). In mice bearing a colon-cancer xenografts, TCOmodified anti-TAG72 mAb CC49 (CC49-TCO) was administrated and 1 day later followed by ${ }^{111}$ In-labeled-DOTA-tetrazine $\left({ }^{111} \mathrm{In}\right.$ tetrazine) at a 1:25 molar ratio. Three hours p.i. of ${ }^{111}$ In-tetrazine, SPECT imaging clearly delineated the tumor with a tumor uptake of $4.2 \% \mathrm{ID} / \mathrm{g}$ and a tumor-to-muscle (T/M) ratio of 13.1 , whereas the tumor uptake of ${ }^{111}$ In-tetrazine and tumor-to-muscle ratio pretargeted with unmodified CC 49 or an irrelevant TCO-modified
$\mathrm{Ab}$ were 0.3 and $0.5 \% \mathrm{ID} / \mathrm{g}$ or 1.0 and $2.1 \% \mathrm{ID} / \mathrm{g}$, respectively (Figure 7).

Zeglis et al. demonstrated that the in vivo click methodology is able to delineate tumors with PET (62). Nude mice with s.c. SW1222 colorectal cancer xenografts were i.v. administrated with TCO-modified A33 Ab $(100 \mu \mathrm{g})$ followed $24 \mathrm{~h}$ later by ${ }^{64} \mathrm{Cu}$-NOTA-tetrazine $(10.2-12.0 \mathrm{MBq})$ or with the directly radiolabeled Ab ${ }^{64} \mathrm{Cu}-\mathrm{NOTA}-\mathrm{A} 33$ (10.2-12 MBq) or ${ }^{89} \mathrm{Zr}-\mathrm{DFO}-\mathrm{A} 33$ (10.2-12.0 MBq). Despite the higher tumor accumulation of the directly labeled antibodies at $24 \mathrm{~h}$ p.i, the pretargeting approach resulted in comparable PET images and tumor-to-muscle ratios (Figure 8). The dose delivered to normal tissues using this pretargeting approach was calculated, indicating that the non-targeted tissues received a significant lower dose when a pretargeting approach $(0.0124 \mathrm{mSv} / \mathrm{MBq})$ was used compared to the directly labeled $\mathrm{Abs},{ }^{64} \mathrm{Cu}-\mathrm{NOTA}-\mathrm{A} 33$, and ${ }^{89} \mathrm{Zr}-\mathrm{DFO}-\mathrm{A} 33$ (0.0359 and $0.4162 \mathrm{mSv} / \mathrm{MBq}$, respectively).

The fast reaction kinetics $\left[k_{2}=13,090 \mathrm{M}^{-1} \mathrm{~s}^{-1}\right.$ (60)] of the IEDDA reaction between the trans-cycloctene and tetrazines are very promising, however, are still significantly lower compared to the association constants of the non-covalent high affinity interactions used in humans $\left(5 \times 10^{5}\right.$ up to $\left.7.5 \times 10^{7} \mathrm{M}^{-1} \mathrm{~s}^{-1}\right)$. In addition, Rossin et al. reported that the TCO can be deactivated through isomerization to the unreactive cis-cyclooctene (CCO) isomer via copper-containing proteins (e.g., transcuprein, mouse serum albumin, ceruloplasmin) (61). TCO tags that are linked to the antibody through an axial substituent afforded a marked increase of the reactivity (61). In conjunction, the stability of the TCO tag could be improved by removal of the PEG linker between the TCO and the lysine residue on the Ab, increasing the steric hindrance on the TCO thus hampering interaction with serum protein-bound copper. The increased reactivity (up to $k_{2}=2.7 \times 10^{5} \mathrm{M}^{-1} \mathrm{~s}^{-1}$ in PBS (61) and improved stability of the IEDDA between a tetrazine and TCO-tagged antibody resulted in an improved tumor-to-blood ratio (61). Devaraj et al. (64) reported that the in vivo reaction yield of a moderately reactive IEDDA system $\left(k_{2}=6 \times 10^{3} \mathrm{M}^{-1} \mathrm{~s}^{-1}\right.$ in PBS $)$ could be improved

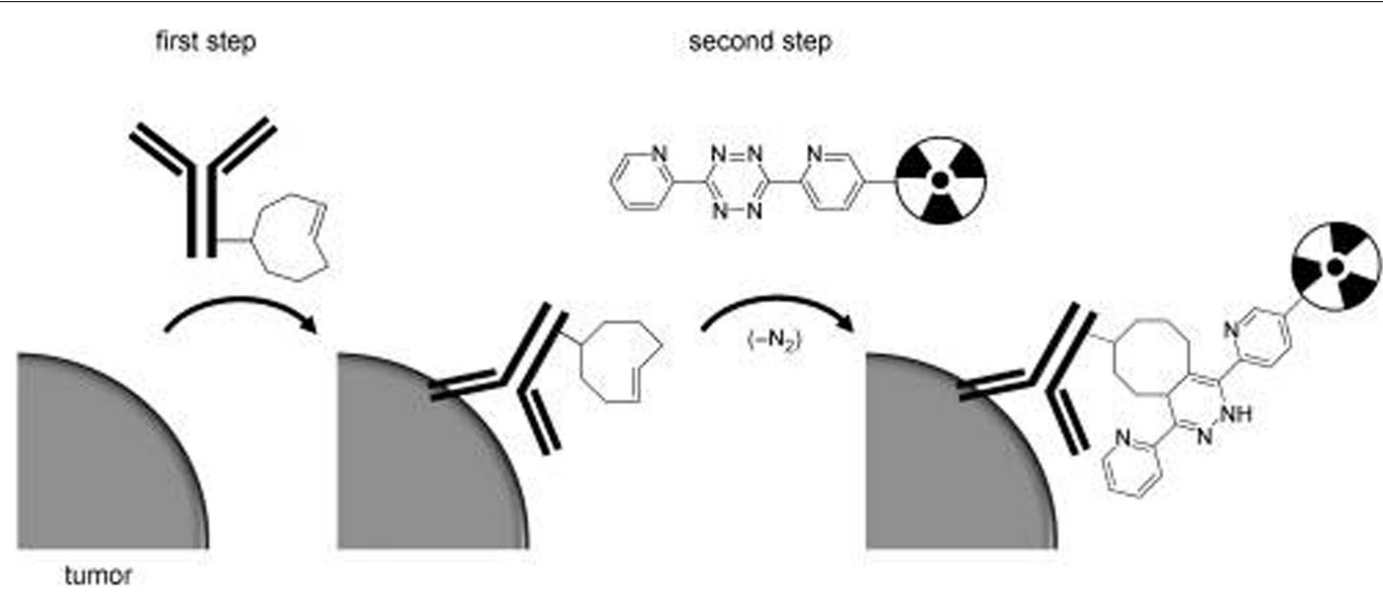

FIGURE 6 | Schematic overview of tumor pretargeting by using the inverse-electron-demand Diels-Alder reaction. This research was originally published in Rossin et al. (60). 
by altering the pharmacokinetics of the radiolabeled probe by polymer conjugation (64). In mice with LS174T xenografts TCOtagged A33 antibody $(30 \mu \mathrm{g})$ was administrated and followed $24 \mathrm{~h}$ later by the ${ }^{18} \mathrm{~F}$-labeled, dextran-based tetrazine probe $(30 \mu \mathrm{g}$; $150 \mu \mathrm{Ci}$ ). PET imaging $3 \mathrm{~h}$ p.i. of the ${ }^{18} \mathrm{~F}$-labeled tracer revealed a

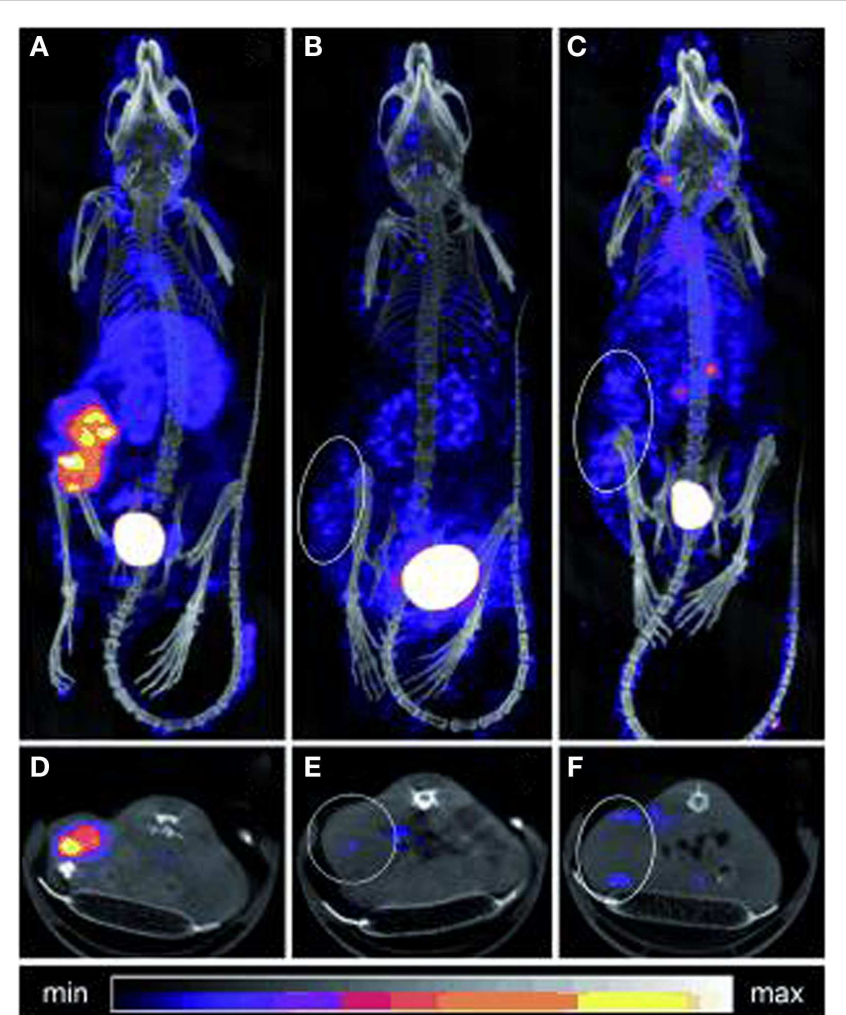

FIGURE 7 | SPECT/CT imaging of mice bearing colon carcinoma xenografts: posterior projections of mice preinjected with (A) CC49-TCO followed 1 day later by ${ }^{111}$ In-DOTA-tetrazine $(1: 25,42 \mathrm{MBq})$, (B) CC49 followed 1 day later by ${ }^{111}$ In-DOTA-tetrazine (1:25, $\left.20 \mathrm{MBq}\right)$, (C) irrelevant Ab (Rtx-TCO; $100 \mu \mathrm{g}$ ) followed 1 day later by

${ }^{111}$ In-DOTA-tetrazine (1:25, $\left.50 \mathrm{MBq}\right)$, (D-F) single transverse slices $(\mathbf{2} \mathbf{~} \mathbf{m})$ passing through the tumors in $(A-C)$. This research was originally published in Rossin et al. (60). significant higher tumor accumulation in TCO-tagged antibody pretargeted mice compared to mice pretargeted with Ab lacking TCO. However, the tumor-to-blood ratio still remained low due to the relative high amount of free-circulating CC49-TCO. For effective tumor targeting, a clearing agent was developed that could clear the TCO-tagged antibody from the circulation prior to administration of the radiolabeled tetrazine (61). In mice with LS174T tumor xenografts, ${ }^{125}$ I-CC49-TCO was injected after which a single or double dose ( $30 \mathrm{~h}$ or 30 and $48 \mathrm{~h}$ after $\mathrm{mAb}$ injection) of the clearing agent, followed $2 \mathrm{~h}$ later by ${ }^{177} \mathrm{Lu}$-tetrazine. Three hours p.i., the blood level of ${ }^{125} \mathrm{I}-\mathrm{CC} 49-\mathrm{TCO}$ was lowest after the double dose of clearing agent $(0.19 \pm 0.04 \% \mathrm{ID} / \mathrm{g})$, followed by the single dose $(1.16 \pm 0.43 \% \mathrm{ID} / \mathrm{g})$ and highest in the group without clearing agent injection $(8.47 \pm 4.12 \% \mathrm{ID} / \mathrm{g})$. The biodistribution of ${ }^{177} \mathrm{Lu}$-tetrazine showed that the elimination of the free CC49-TCO in combination with a reduced amount of tetrazine (from 17 to $6.7 \mathrm{nmol}$ ) significantly improved the tumor uptake from $3.12 \pm 0.87 \% \mathrm{ID} / \mathrm{g}(60)$ to $7.45 \pm 1.46 \% \mathrm{ID} / \mathrm{g}$ for the single dose and to $6.13 \pm 1.09 \% \mathrm{ID} / \mathrm{g}$ for the double dose of clearing agent. Both single as well as the double dose approach significantly increased the tumor-to-muscle and tumor-to-blood ratios compared to the previous approach without clearing agent. In fact, a 125-fold improvement of the tumor-to-blood ratio at $3 \mathrm{~h}$ after tetrazine injection was achieved with a double dose of clearing agent. Corresponding mouse dosimetry experiments suggested that at MTD for bone marrow (dose-limiting organ for both approaches), this should allow for an eightfold higher tumor dose than is possible with non-pretargeted RIT. The estimated dose to the tumor in mice with directly ${ }^{177} \mathrm{Lu}$-labeled CC49 is significantly higher compared to the pretargeted approach using CC49-TCO and ${ }^{177} \mathrm{Lu}-\mathrm{Tz}$ (9573 vs. $479 \mathrm{mGy} / \mathrm{MBq}$ ). However, also the normal tissues receive high doses, for example, the bone marrow receive $1136 \mathrm{mGy} / \mathrm{MBq}$, whereas in the pretargeting approach the bone marrow dose is $7 \mathrm{mGy} / \mathrm{MBq}$. Subsequently, this system was further improved by modifying the pharmacokinetics of the tagged antibody and by increasing the stability of the tag. The use of a more hydrophilic tag with an increased in vivo tag stability $\left(t_{1 / 2}=10\right.$ days $)$ afforded a slower clearing CC49-TCO conjugate with increased tumor targeting, resulting in a $50 \%$ increased tumor uptake and $\mathrm{T} / \mathrm{NT}$ ratios of the tetrazine probe (65). So far, the reaction of TCO with 1,2,4,5-tetrazines is the
${ }^{64} \mathrm{Cu}-\mathrm{Tz}-\mathrm{Bn}-\mathrm{NOTA} / \mathrm{A33}-\mathrm{TCO}$

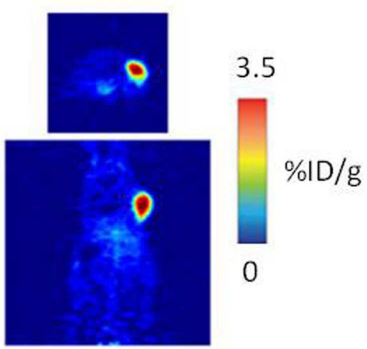

${ }^{64} \mathrm{Cu}-\mathrm{Tz}-\mathrm{Bn}-\mathrm{NOTA}$

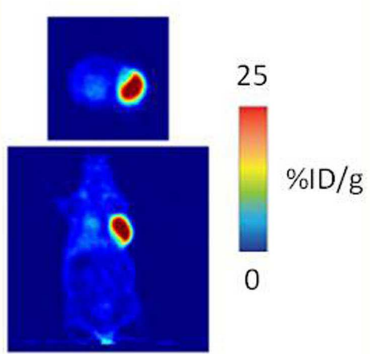

${ }^{89} \mathrm{Zr}$-DFO-A33

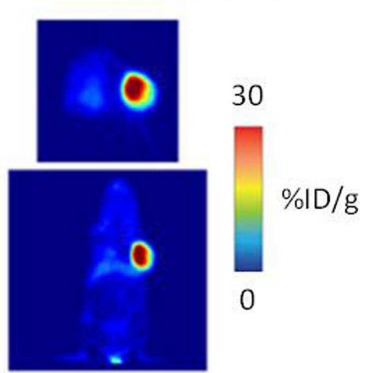

FIGURE 8 | PET images of 64Cu-Tz-Bn-NOTA/A33-TCO pretargeting strategy, 64Cu-NOTA-A33 and 89Zr-DFO-A33.Transverse (top) and coronal (bottom) planar images intersect the center of the tumors. This research was originally published in Zeglis et al. (63). 
fastest bioorthogonal reaction (61). While others were unsuccessful in enlisting the slower SPAAC for antibody-based pretargeting in mice (62), Lee et al. reported a pretargeting system consisting of aza-dibenzocyclooctynes modified mesoporous silica nanoparticles in combination with ${ }^{18} \mathrm{~F}$-azide and achieved tumor uptake in mice, possibly due to the high loading capacity of the mesoporous particles (66). Further work is required to establish whether the fastest cyclooctynes enable efficient SPAAC-based pretargeting with antibodies as well.

\section{CONCLUSION}

Clinical studies revealed that the pretargeting approach based on bsAb directed against a tumor-associated antigen and against HSG in combination with radiolabeled (divalent) peptides containing the HSG residue resulted in high contrast images. Therefore, the use of this pretargeting system is very promising for non-invasive imaging of tumors before, during, and after therapy. Additionally, pretargeted RIT using this system is capable to inhibit tumor growth with minor toxicity. However, to fully develop this pretargeting approach in the clinic research should focus on the best regime and protocol. Although several comparative studies between a pretargeting approach and directly radiolabeled antibodies have been performed, further quantitative comparative studies are needed to evaluate the potential of the pretargeted imaging and therapy. Furthermore, preclinical studies using bioorthogonal chemical pretargeting based on the inverse Diels-Alder cycloaddition revealed that tumors can be imaged and treated with this new approach. This approach is still being further optimized and clinical studies are warranted to determine the potential of this new strategy.

\section{REFERENCES}

1. Fleuren EDG, Versleijen-Jonkers YMH, Heskamp S, van Herpen CML, Oyen WJG, van der Graaf WTA, et al. Theranostic applications of antibodies in oncology. Mol Oncol (2014) 8(4):799-812. doi:10.1016/j.molonc.2014.03.010

2. Heskamp S, van Laarhoven HW, Oyen WJ, van der Graaf WT, Boerman OC. Tumor-receptor imaging in breast cancer: a tool for patient selection and response monitoring. Curr Mol Med (2013) 13(10):1506-22. doi:10.2174/ 1566524013666131111120638

3. Goldenberg DM, Sharkey RM. Using antibodies to target cancer therapeutics. Expert Opin Biol Ther (2012) 12(9):1173-90. doi:10.1517/14712598.2012. 693472

4. Boerman OC, van Schaijk FG, Oyen WJG, Corstens FHM. Pretargeted radioimmunotherapy of cancer: progress step by step. J Nucl Med (2003) 44(3):400-11.

5. Kong F-L, Ford RJ, Yang DJ. Managing lymphoma with non-FDG radiotracers: current clinical and preclinical applications. Biomed Res Int (2013) 2013:12. doi:10.1155/2013/626910

6. Sharkey R, Chang C-H, Rossi E, McBride W, Goldenberg D. Pretargeting: taking an alternate route for localizing radionuclides. Tumor Biol (2012) 33(3):591-600. doi:10.1007/s13277-012-0367-6

7. Hnatowich DJ, Virzi F, Rusckowski M. Investigations of avidin and biotin for imaging applications. J Nucl Med (1987) 28(8):1294-302.

8. Liu G, Dou S, Baker S, Akalin A, Cheng D, Chen L, et al. A preclinical 188Re tumor therapeutic investigation using MORF/cMORF pretargeting and an antiTAG72 antibody CC49. Cancer Biol Ther (2010) 10(8):767-74. doi:10.4161/cbt.10. 8.12879

9. Liu G, Dou S, Pretorius PH, Liu X, Chen L, Rusckowski M, et al. Tumor pretargeting in mice using MORF conjugated CC49 antibody and radiolabeled complimentary cMORF effector. Q J Nucl Med Mol Imaging (2010) 54(3):333-40.

10. He J, Wang Y, Dou S, Liu X, Zhang S, Liu G, et al. Affinity enhancement pretargeting: synthesis and testing of a 99mTc-labeled bivalent MORF. Mol Pharm (2010) 7(4):1118-24. doi:10.1021/mp9002909
11. He J, Liu G, Gupta S, Zhang Y, Rusckowski M, Hnatowich DJ. Amplification targeting: a modified pretargeting approach with potential for signal amplification - proof of a concept. J Nucl Med (2004) 45(6):1087-95.

12. Carroll L, Evans HL, Aboagye EO, Spivey AC. Bioorthogonal chemistry for pretargeted molecular imaging - progress and prospects. Org Biomol Chem (2013) 11(35):5772-81. doi:10.1039/c3ob40897c

13. King M, Wagner A. Developments in the field of bioorthogonal bond forming reactions-past and present trends. Bioconjug Chem (2014) 25(5):825-39. doi:10.1021/bc500028d

14. Förster GJ, Santos EB, Smith-Jones PM, Zanzonico P, Larson SM. Pretargeted radioimmunotherapy with a single-chain antibody/streptavidin construct and radiolabeled DOTA-biotin: strategies for reduction of the renal dose. J Nucl Med (2006) 47(1):140-9.

15. Reardan DT, Meares CF, Goodwin DA, McTigue M, David GS, Stone MR, et al. Antibodies against metal chelates. Nature (1985) 316(6025):265-8. doi:10.1038/ $316265 \mathrm{a} 0$

16. Boerman OC, Kranenborg MHGC, Oosterwijk E, Griffiths GL, McBride WJ, Oyen WJG, et al. Pretargeting of renal cell carcinoma: improved tumor targeting with a bivalent chelate. Cancer Res (1999) 59(17):4400-5.

17. Primus FJ, Wang RH, Goldenberg DM, Hansen HJ. Localization of human GW39 tumors in hamsters by radiolabeled heterospecific antibody to carcinoembryonic antigen. Cancer Res (1973) 33(11):2977-82.

18. Baxter LT, Jain RK. Transport of fluid and macromolecules in tumors. I. Role of interstitial pressure and convection. Microvasc Res (1989) 37(1):77-104. doi:10.1016/0026-2862(89)90074-5

19. Stickney DR, Anderson LD, Slater JB, Ahlem CN, Kirk GA, Schweighardt SA, et al. Bifunctional antibody: a binary radiopharmaceutical delivery system for imaging colorectal carcinoma. Cancer Res (1991) 51(24):6650-5.

20. Chang CH, Sharkey RM, Rossi EA, Karacay H, McBride W, Hansen HJ, et al. Molecular advances in pretargeting radioimunotherapy with bispecific antibodies. Mol Cancer Ther (2002) 1(7):553-63.

21. Karacay H, Sharkey RM, McBride WJ, Griffiths GL, Qu Z, Chang K, et al. Pretargeting for cancer radioimmunotherapy with bispecific antibodies:? role of the bispecific antibody's valency for the tumor target antigen. Bioconjug Chem (2002) 13(5):1054-70. doi:10.1021/bc0200172

22. Le Doussal JM, Martin M, Gautherot E, Delaage M, Barbet J. In vitro and in vivo targeting of radiolabeled monovalent and divalent haptens with dual specificity monoclonal antibody conjugates: enhanced divalent hapten affinity for cell-bound antibody conjugate. J Nucl Med (1989) 30(8):1358-66.

23. Le Doussal JM, Gruaz-Guyon A, Martin M, Gautherot E, Delaage M, Barbet J. Targeting of indium 111-labeled bivalent hapten to human melanoma mediated by bispecific monoclonal antibody conjugates: imaging of tumors hosted in nude mice. Cancer Res (1990) 50(11):3445-52.

24. Kraeber-Bodere F, Bardet S, Hoefnagel CA, Vieira MR, Vuillez JP, Murat A, et al. Radioimmunotherapy in medullary thyroid cancer using bispecific antibody and iodine 131-labeled bivalent hapten: preliminary results of a phase I/II clinical trial. Clin Cancer Res (1999) 5(10 Suppl):3190s-8s.

25. Barbet J, Peltier P, Bardet S, Vuillez JP, Bachelot I, Denet S, et al. Radioimmunodetection of medullary thyroid carcinoma using indium-111 bivalent hapten and anti-CEA $x$ anti-DTPA-indium bispecific antibody. J Nucl Med (1998) 39(7):1172-8.

26. Goodwin DA, Meares CF, Watanabe N, McTigue M, Chaovapong W, Ransone CM, et al. Pharmacokinetics of pretargeted monoclonal antibody 2D12.5 and 88Y-Janus-2-(p-nitrobenzyl)-1,4,7,10-tetraazacyclododecanetetraacetic acid (DOTA) in BALB/c mice with KHJJ mouse adenocarcinoma: a model for $90 \mathrm{Y}$ radioimmunotherapy. Cancer Res (1994) 54(22):5937-46.

27. Le Doussal JM, Barbet J, Delaage M. Bispecific-antibody-mediated targeting of radiolabeled bivalent haptens: theoretical, experimental and clinical results. Int J Cancer Suppl (1992) 7:58-62.

28. Le Doussal JM, Gautherot E, Martin M, Barbet J, Delaage M. Enhanced in vivo targeting of an asymmetric bivalent hapten to double-antigen-positive mouse B cells with monoclonal antibody conjugate cocktails. J Immunol (1991) 146(1):169-75.

29. Le Doussal JM, Chetanneau A, Gruaz-Guyon A, Martin M, Gautherot E, Lehur $\mathrm{PA}$, et al. Bispecific monoclonal antibody-mediated targeting of an indium-111labeled DTPA dimer to primary colorectal tumors: pharmacokinetics, biodistribution, scintigraphy and immune response. J Nucl Med (1993) 34(10): $1662-71$. 
30. Bardies M, Bardet S, Faivre-Chauvet A, Peltier P, Douillard JY, Mahe M, et al. Bispecific antibody and iodine-131-labeled bivalent hapten dosimetry in patients with medullary thyroid or small-cell lung cancer. J Nucl Med (1996) 37(11):1853-9.

31. Doussal J-ML, Gruaz-Guyon A, Martin M, Gautherot E, Delaage M, Barbet J. Targeting of Indium 111-labeled bivalent hapten to human melanoma mediated by bispecific monoclonal antibody conjugates: imaging of tumors hosted in nude mice. Cancer Res (1990) 50(11):3445-52.

32. Sharkey RM, McBride WJ, Karacay H, Chang K, Griffiths GL, Hansen HJ, et al. A universal pretargeting system for cancer detection and therapy using bispecific antibody. Cancer Res (2003) 63(2):354-63.

33. Janevik-Ivanovska E, Gautherot E, Hillairet de Boisferon M, Cohen M, Milhaud G, Tartar A, et al. Bivalent hapten-bearing peptides designed for iodine131 pretargeted radioimmunotherapy. Bioconjug Chem (1997) 8(4):526-33. doi:10.1021/bc970083h

34. Hosono M, Hosono MN, Kraeber-Bodere F, Devys A, Thedrez P, Faivre-Chauvet A, et al. Two-step targeting and dosimetry for small cell lung cancer xenograft with anti-NCAM/antihistamine bispecific antibody and radioiodinated bivalent hapten. J Nucl Med (1999) 40(7):1216-21.

35. McBride WJ, Zanzonico P, Sharkey RM, Noren C, Karacay H, Rossi EA, et al. Bispecific antibody pretargeting PET (immunoPET) with an 124I-labeled haptenpeptide. J Nucl Med (2006) 47(10):1678-88.

36. Griffiths GL, Chang CH, McBride WJ, Rossi EA, Sheerin A, Tejada GR, et al. Reagents and methods for PET using bispecific antibody pretargeting and $68 \mathrm{Ga}-$ radiolabeled bivalent hapten-peptide-chelate conjugates. J Nucl Med (2004) 45(1):30-9.

37. Karacay H, Sharkey RM, McBride WJ, Rossi EA, Chang CH, Goldenberg DM. Optimization of hapten-peptide labeling for pretargeted immunoPET of bispecific antibody using generator-produced 68Ga. J Nucl Med (2011) 52(4):555-9. doi:10.2967/jnumed.110.083568

38. McBride WJ, D’Souza CA, Sharkey RM, Goldenberg DM. The radiolabeling of proteins by the [18F]AlF method. Appl Radiat Isot (2012) 70(1):200-4. doi:10.1016/j.apradiso.2011.08.013

39. Rossi EA, Chang CH, Losman MJ, Sharkey RM, Karacay H, McBride W, et al. Pretargeting of carcinoembryonic antigen-expressing cancers with a trivalent bispecific fusion protein produced in myeloma cells. Clin Cancer Res (2005) 11(19 Pt 2):7122s-9s. doi:10.1158/1078-0432.CCR-1004-0020

40. Rossi EA, Goldenberg DM, Cardillo TM, McBride WJ, Sharkey RM, Chang CH. Stably tethered multifunctional structures of defined composition made by the dock and lock method for use in cancer targeting. Proc Natl Acad Sci U S A (2006) 103(18):6841-6. doi:10.1073/pnas.0600982103

41. Chang C-H, Rossi EA, Goldenberg DM. The dock and lock method: a novel platform technology for building multivalent, multifunctional structures of defined composition with retained bioactivity. Clin Cancer Res (2007) 13(18):5586s-91s. doi:10.1158/1078-0432.CCR-07-1217

42. Goldenberg DM, Rossi EA, Sharkey RM, McBride WJ, Chang CH. Multifunctional antibodies by the dock-and-lock method for improved cancer imaging and therapy by pretargeting. J Nucl Med (2008) 49(1):158-63. doi:10.2967/ jnumed.107.046185

43. Sharkey RM, Karacay H, Vallabhajosula S, McBride WJ, Rossi EA, Chang CH, et al. Metastatic human colonic carcinoma: molecular imaging with pretargeted SPECT and PET in a mouse model. Radiology (2008) 246(2):497-507. doi:10.1148/radiol.2462070229

44. Karacay H, Brard PY, Sharkey RM, Chang CH, Rossi EA, McBride WJ, et al. Therapeutic advantage of pretargeted radioimmunotherapy using a recombinant bispecific antibody in a human colon cancer xenograft. Clin Cancer Res (2005) 11(21):7879-85. doi:10.1158/1078-0432.CCR-05-1246

45. van Rij CM, Lutje S, Frielink C, Sharkey RM, Goldenberg DM, Franssen GM, et al. Pretargeted immuno-PET and radioimmunotherapy of prostate cancer with an anti-TROP-2 $\mathrm{x}$ anti-HSG bispecific antibody. Eur J Nucl Med Mol Imaging (2013) 40(9):1377-83. doi:10.1007/s00259-013-2434-7

46. Sharkey RM, Karacay H, Litwin S, Rossi EA, McBride WJ, Chang C-H, et al. Improved therapeutic results by pretargeted radioimmunotherapy of NonHodgkin's lymphoma with a new recombinant, trivalent, anti-CD20, bispecific antibody. Cancer Res (2008) 68(13):5282-90. doi:10.1158/0008-5472.CAN-080037

47. Cardillo TM, Karacay H, Goldenberg DM, Yeldell D, Chang C-H, Modrak DE, et al. Improved targeting of pancreatic cancer: experimental studies of a new bispecific antibody, pretargeting enhancement system for immunoscintigraphy. Clin Cancer Res (2004) 10(10):3552-61. doi:10.1158/1078-0432.CCR-03-0340

48. Schoffelen R, Sharkey RM, Goldenberg DM, Franssen G, McBride WJ, Rossi EA, et al. Pretargeted immuno-positron emission tomography imaging of carcinoembryonic antigen-expressing tumors with a bispecific antibody and a $68 \mathrm{Ga}$ and $18 \mathrm{~F}$-labeled hapten peptide in mice with human tumor xenografts. $\mathrm{Mol}$ Cancer Ther (2010) 9(4):1019-27. doi:10.1158/1535-7163.MCT-09-0862

49. Schoffelen R, van der Graaf WT, Sharkey RM, Franssen GM, McBride WJ, Chang $\mathrm{CH}$, et al. Pretargeted immuno-PET of CEA-expressing intraperitoneal human colonic tumor xenografts: a new sensitive detection method. EJNMMI Res (2012) 2:5. doi:10.1186/2191-219X-2-5

50. Schoffelen R, van der Graaf WTA, Franssen G, Sharkey RM, Goldenberg DM, McBride WJ, et al. Pretargeted 177Lu radioimmunotherapy of carcinoembryonic antigen-expressing human colonic tumors in mice. J Nucl Med (2010) 51(11):1780-7. doi:10.2967/jnumed.110.079376

51. Schoffelen R, van der Graaf WT, Sharkey RM, Franssen GM, McBride WJ, Chang $\mathrm{CH}$, et al. Quantitative immuno-SPECT monitoring of pretargeted radioimmunotherapy with a bispecific antibody in an intraperitoneal nude mouse model of human colon cancer. J Nucl Med (2012) 53(12):1926-32. doi:10.2967/jnumed.112.106278

52. Schoffelen R, Boerman OC, Goldenberg DM, Sharkey RM, van Herpen CM, Franssen GM, et al. Development of an imaging-guided CEA-pretargeted radionuclide treatment of advanced colorectal cancer: first clinical results. $\mathrm{Br}$ J Cancer (2013) 109(4):934-42. doi:10.1038/bjc.2013.376

53. Ocean AJ, Pennington KL, Guarino MJ, Sheikh A, Bekaii-Saab T, Serafini AN, et al. Fractionated radioimmunotherapy with (90) Y-clivatuzumab tetraxetan and low-dose gemcitabine is active in advanced pancreatic cancer: a phase 1 trial. Cancer (2012) 118(22):5497-506. doi:10.1002/cncr.27592

54. Sletten EM, Bertozzi CR. From mechanism to mouse: a tale of two bioorthogonal reactions. Acc Chem Res (2011) 44(9):666-76. doi:10.1021/ar200148z

55. Borrmann A, van Hest JCM. Bioorthogonal chemistry in living organisms. Chem Sci (2014) 5(6):2123-34. doi:10.1039/c3sc52768a

56. Reiner T, Zeglis BM. The inverse electron demand Diels-Alder click reaction in radiochemistry. J Labelled Comp Radiopharm (2014) 57(4):285-90. doi:10.1002/jlcr.3149

57. Kolb HC, Finn MG, Sharpless KB. Click chemistry: diverse chemical function from a few good reactions. Angew Chem Int Ed (2001) 40(11):2004-21. doi:10.1002/1521-3773(20010601)40:11<2004::AID-ANIE2004>3.0.CO;2-5

58. Gill HS, Marik J. Preparation of 18F-labeled peptides using the copper(I)-catalyzed azide-alkyne 1,3-dipolar cycloaddition. Nat Protoc (2011) 6(11):1718-25. doi:10.1038/nprot.2011.390

59. Devaraj NK, Upadhyay R, Haun JB, Hilderbrand SA, Weissleder R. Fast and sensitive pretargeted labeling of cancer cells through a tetrazine/trans-cyclooctene cycloaddition. Angew Chem Int Ed (2009) 48(38):7013-6. doi:10.1002/anie. 200903233

60. Rossin R, Verkerk PR, van den Bosch SM, Vulders RC, Verel I, Lub J, et al. In vivo chemistry for pretargeted tumor imaging in live mice. Angew Chem Int Ed Engl (2010) 49(19):3375-8. doi:10.1002/anie.201001645

61. Rossin R, van den Bosch SM, ten Hoeve W, Carvelli M, Versteegen RM, Lub J, et al. Highly reactive trans-cyclooctene tags with improved stability for Diels-Alder chemistry in living systems. Bioconjug Chem (2013) 24(7):1210-7. doi:10.1021/bc400153y

62. van den Bosch SM, Rossin R, Renart Verkerk P, Ten Hoeve W, Janssen HM, Lub J, et al. Evaluation of strained alkynes for $\mathrm{Cu}$-free click reaction in live mice. $\mathrm{Nucl}$ Med Biol (2013) 40:415-23. doi:10.1016/j.nucmedbio.2012.12.006

63. Zeglis BM, Sevak KK, Reiner T, Mohindra P, Carlin SD, Zanzonico P, et al. A pretargeted PET imaging strategy based on bioorthogonal diels-alder click chemistry. J Nucl Med (2013) 54(8):1389-96. doi:10.2967/jnumed.112.115840

64. Devaraj NK, Thurber GM, Keliher EJ, Marinelli B, Weissleder R. Reactive polymer enables efficient in vivo bioorthogonal chemistry. Proc Natl Acad Sci U S A (2012) 109(13):4762-7. doi:10.1073/pnas.1113466109

65. Rossin R, van Duijnhoven SM, Läppchen T, van den Bosch SM, Robillard MS. Trans-cyclooctene tag with improved properties for tumor pretargeting with the Diels-Alder reaction. Mol Pharm (2014) 11(9):3090-6. doi:10.1021/mp500275a 66. Lee SB, Kim HL, Jeong H-J, Lim ST, Sohn M-H, Kim DW. Mesoporous silica nanoparticle pretargeting for pet imaging based on a rapid bioorthogonal reaction in a living body. Angew Chem Int Ed Engl (2013) 52(40):10549-52. doi:10.1002/anie.201304026 
Conflict of Interest Statement: The authors declare that the research was conducted in the absence of any commercial or financial relationships that could be construed as a potential conflict of interest.

Received: 04 September 2014; accepted: 22 October 2014; published online: 18 November 2014.

Citation: van de Watering FCJ, Rijpkema M, Robillard M, Oyen WJG and Boerman OC (2014) Pretargeted imaging and radioimmunotherapy of cancer using antibodies and bioorthogonal chemistry. Front. Med. 1:44. doi: 10.3389/fmed.2014.00044
This article was submitted to Nuclear Medicine, a section of the journal Frontiers in Medicine.

Copyright (C) 2014 van de Watering, Rijpkema, Robillard, Oyen and Boerman. This is an open-access article distributed under the terms of the Creative Commons Attribution License (CC BY). The use, distribution or reproduction in other forums is permitted, provided the original author(s) or licensor are credited and that the original publication in this journal is cited, in accordance with accepted academic practice. No use, distribution or reproduction is permitted which does not comply with these terms. 